
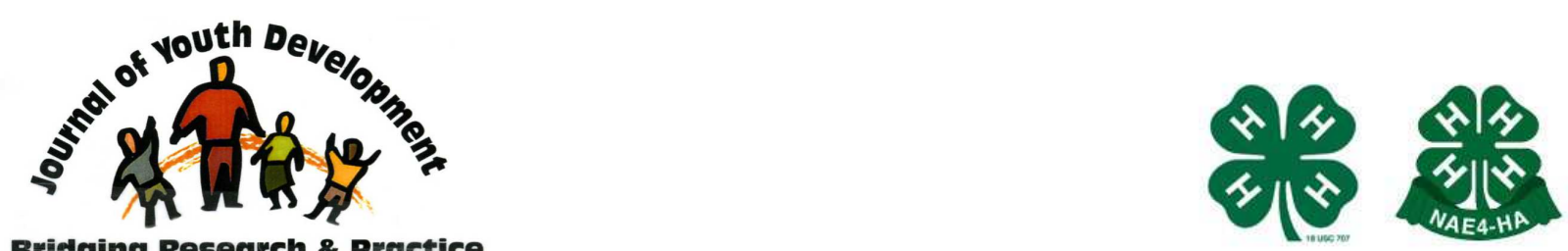

\title{
Rethinking Concept Mapping for Youth Participatory Evaluation in the Context of Youth Development Programs
}

Jennifer Southwick Brown

Department of Human Development

Cornell University

JSB75@cornell.edu 


\section{JOURNAL OF YOUTH DEVELOPMENT \\ bridging research and practice

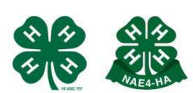

Volume 1, Number 2, September 2006

Article 0602RS001

\section{Rethinking Concept Mapping for Youth Participatory Evaluation in the Context of Youth Development Programs}

Jennifer Southwick Brown

Cornell University

Abstract: As a mixed-methods participatory approach, concept mapping (Trochim, 1989) provides unique opportunities for engaging youth in evaluating the contexts and environments in which they develop. Youth development programs, by definition, seek to fully engage youth as partners and provide them with opportunities to effect positive change. This includes encouraging youth to be involved in the process of designing, implementing, and evaluating the programs and activities in which they participate. Concept mapping has been used successfully with adult populations; however its utility with adolescents in the context of youth development programming has yet to be explored. This paper explores both the obstacles and successes associated with utilizing this participatory approach with youth.

\section{Evaluating Youth Development Programs}

In order to determine whether a program has an impact, we must have clear outcomes or indicators of successful development. Traditionally, positive outcomes have been measured by the absence of behavioral problems. More recently, efforts are being made to measure the presence of healthy development (National Research Council \& Institute of Medicine, 2002).

Any evaluation of youth development programs should include the input of the youth themselves in order to follow the fundamental principle of youth participation and empowerment (Benson, Scales, Hamilton, \& Sesma, 2006). A youth participatory evaluation methodology is needed that allows youth to have a voice in the evaluation of programs in which they participate.

\section{The Importance of a Collaborative Approach}

Community-based participatory research (CBPR) methods confirm that practitioners and community members are more likely to embrace the results of research if they have been 
actively engaged in the research process (Green \& Mercer, 2001; Krieger, et al., 2002; Wallerstein, 1999). Typically, policy makers control the resources and thus are the primary decision makers. Researchers are responsible for determining the areas worthy of study. CBPR attempts to adjust the scales so that all stakeholders equally share power, funds, and responsibility (Lantz, Viruell-Fuentes, Isreal, Softley, \& Guzman, 2001). Each participant adds important expertise to any research endeavor, and in particular can increase understanding and enhance the quality of research (Eisinger \& Senturia, 2001; Higgins \& Metzler, 2001; Macaulay et al., 1999).

\section{Concept Mapping as a Youth Participatory Evaluation Tool}

At its core, concept mapping is a participatory approach that enables large groups of people from a variety of perspectives to reach consensus while minimizing the differentiation of power between the groups. Concept mapping ensures that all participants have an equal voice and that one person or group does not dominate the process or outcomes. Although concept mapping is not traditionally used with youth or in the context of evaluating youth programs, it has the potential to be an ideal tool for use in this context. If properly designed, concept mapping enables and encourages youth voice and youth empowerment.

\section{Overview of the Concept Mapping Methodology}

Concept mapping (Trochim, 1989) is a descriptive approach that utilizes qualitative data but also includes a quantitative component using multidimensional scaling and hierarchical cluster analysis. Concept mapping involves the following stages:

1. Preparation includes generating the focus prompt (an open-ended sentence that participants are asked to complete), determining the participants and how they will be contacted, and setting the project schedule.

2. Generation of brainstormed statements in response to a focus prompt.

3. Structuring of issues which includes sorting and rating statements on the dimension of importance and (for the purposes of the study in the following example) consistency with YD principles. Participants are also asked to answer several questions that will enable subgroup analysis.

4. Analysis and pre-interpretation of participant input involves a sequence of multivariate statistical methods including multidimensional scaling and hierarchical cluster analysis.

5. Interpretation of results occurs in a facilitated session that follows a prescribed sequence of steps.

\section{Concept Mapping in a Youth Development Context: An Example}

The following is an example of an exploratory study of a collaborative approach to understanding the characteristics of successful youth development programs. This study marks an initial step toward developing measurable indicators of positive development. Participants included policy makers, practitioners, researchers, and youth who were involved at some level (employed, studied, or participated) in programs that aim to foster positive youth development.

A total of 163 people participated in at least some aspect of the study. The group was comprised of 22 policy makers (13.5\%), 72 practitioners (44.2\%), 31 researchers $(19.0 \%), 34$ 
youth (20.9\%), and 4 people (2.4\%) who did not associate with any of the 4 groups already mentioned.

All of the participants were asked to brainstorm in response to the following focus prompt: "A specific characteristic or component of a successful adolescent/youth program is..." Note that the focus prompt asks that participants consider characteristics of successful adolescent/youth programs in general. It does not specifically ask about youth development programs. This was done to ensure that the youth participants could understand and participate in the brainstorming and sorting phase of the study. The youth development concept emerges in the rating activity and is discussed in greater detail below. The goal was to differentiate between successful youth programs in general and youth development programs in particular.

The youth were not expected to differentiate between youth programs in general and youth development programs in particular. All of the youth were current participants in a youth development program. Their involvement in other youth programs (which may or may not have had a focus on promoting positive youth development) was not known. For the purposes of this study, it was not necessary for the youth to differentiate between youth development programs and other youth programs. The goal was to ascertain the components of youth programs that the youth themselves deemed important. The adults in the study were subsequently asked to distinguish those components of successful youth programs that are specific to youth development programs. In order to ensure youth participation in the study to the fullest extent possible, the focus prompt was worded in such a way that the youth could understand the task and provide critical feedback.

The policy makers, practitioners, and researchers were asked to individually generate between 5 and 10 statements in response to the prompt, fill in a brainstorming form, and return it via email. The youth completed the brainstorming activity in a format that differed from that used for adults. Youth brainstorming was conducted during an in-person, facilitated brainstorming session held at their program location. The in-person facilitation technique was used with the youth in order to further engage them in the process. Youth who may not usually participate in activities were encouraged to generate ideas and they had an opportunity to discuss as a group the aspects of their own program that are successful.

At least two researchers were present for each brainstorming session. The focus prompt was projected on a screen and the youth were asked to take a few minutes to individually write down several responses to the prompt. The primary facilitator then went around the room and asked each participant to read aloud one of their statements. The second researcher entered each of the statements verbatim into a word document that was projected on a screen. The facilitator went around the room several times asking the participants to read one of their statements. The facilitator then read through the list of generated statements and asked if there was anything else that anyone wanted to add.

In total, 1,075 statements were generated by all of the participants. In line with the concept mapping methodology, these statements were subsequently edited and reduced to a final set of 100 statements that represents the details present in the original brainstormed set. Keywords in Context (KWIC; a software program developed by William Trochim) was used in conjunction with a novel synthesis technique to reduce the statement set (Brown, 2005).

A subset of the adult participants subsequently rated each of the 100 statements for relative importance (on a 1 to 5 Likert-type scale) and a dichotomous variable (yes/no) that asked 
whether each statement was in line with their conception of youth development. A subset of adult participants also individually sorted the statements based upon conceptual similarity.

All of the youth participants were asked to complete the sorting activity and the rating on relative importance. A team of researchers returned to the youth program sites to facilitate the sorting and rating activities. The youth were not asked to complete the youth development rating because they were not expected to differentiate between successful youth programs in general and youth development programs specifically.

After the initial data analysis was completed, representatives from each participant group were invited to attend an interpretation session. The purpose of this session was to view and discuss the initial construct map, to assign cluster names, and to explore the consensus analysis. Youth were actively engaged in this process. Participants in the interpretation session decided on the following cluster names: Ongoing program monitoring and assessment, Broad-based community involvement, Program structure, Innovative strength-based principles, Welcoming environment and family engagement, Expectations of youth workers, Empowering youth friendly environment, Youth leadership opportunities, Promotes individuality and connectedness, and Opportunities for life skills development. For a more detailed discussion of the results see the ACT for Youth website (Brown, 2006).

\section{Outcomes}

Across the statement set, youth and researchers tended to rate statements differently than both practitioners and policy makers (figure 1).

Figure 1

\section{Clusters of Characteristics of Successful Youth Programs: Group Differences in Importance Ratings Ladder Graph}

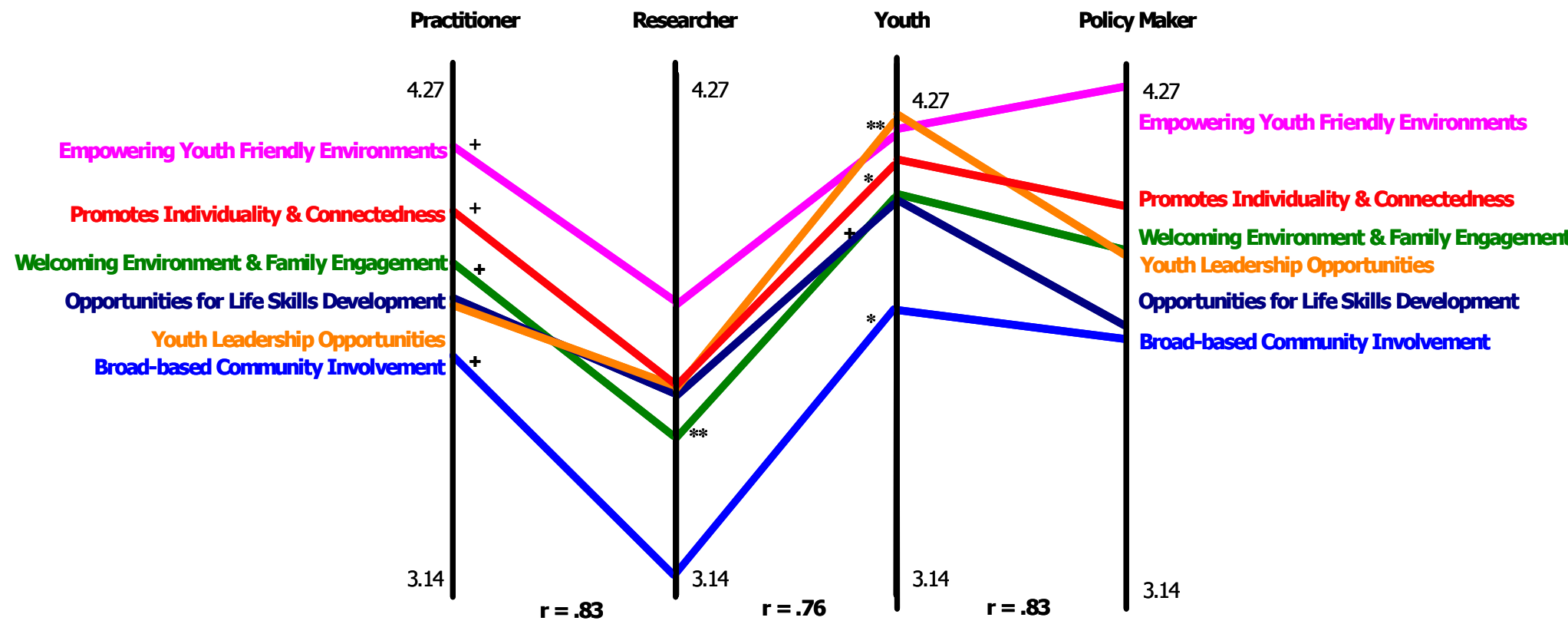

$+\mathrm{p}<.1, * \mathrm{p}<.05, * * \mathrm{p}<.01, * * * \mathrm{p}<.001$

Youth consistently rated statements as higher in importance than both practitioners and researchers. For example, youth viewed youth leadership opportunities as significantly more important than both researchers and practitioners. Youth also rated statements pertaining to 
community involvement and connectedness as higher in importance than both researchers and practitioners. Taken together, these results indicate the need to include a youth voice in any research endeavor that has a direct impact on programming for youth.

\section{Obstacles}

There were a few notable obstacles we encountered while using the concept mapping methodology with a youth population. The most obvious barrier to participation was the level of language used in the statement set. There were several, complex and long statements that were most likely generated by a member of one of the adult subgroups. During the sorting and rating activity, many youth asked for clarification of terminology and appeared to struggle with the conceptual meaning of some of the statements. The data suggest that their degree of conceptual understanding of the statement set may have had an impact on how they completed their sorts. The youth sorted the statement set significantly differently than the practitioners, researchers, and policy makers. One possible solution to this problem would be to have the youth engage in the statement synthesis process in order to monitor the level of language used in the final statement set. This suggests that when working with youth populations the language should be written at an appropriate level for all of the participants.

Another notable barrier to youth participation in concept mapping is the sheer number of statements in the set. Traditionally, concept mapping projects use statement sets that do not exceed 100 statements. This may be too many statements when working with a youth population. Many youth had trouble focusing for the length of time required to sort and rate 100 statements. Some of the youth may also have struggled with the statements due to the abstract thinking skills required to interpret meaning. Fewer and simpler statements would make it easier for the youth to concentrate and would remove some of the cognitive barriers. This study employed a normative population; these issues may become even more pronounced when working with populations of at-risk youth.

\section{Successes}

One of the major benefits of the concept mapping approach is that it allows youth to engage in a research endeavor with adults. The youth were not simply tokens, but rather, their opinions were fully integrated into the research process and weighted equally with the opinions of the other participant groups. One of the primary tenets of youth development programs is youth engagement and empowerment. Concept mapping supports this philosophy by engaging youth in the process of evaluating the programs in which they participate.

Concept mapping also has the potential to be used to explore and address a variety of other research and/or practical questions that arise within the context of a youth development program. For example, concept mapping can be used as part of the planning phase for a youth led action research project. Concept mapping can be used to ascertain the opinions of multiple participants, organize the information into interpretable data, and provide guidance for future action. In particular, the rigor of the methodology provides the data often needed to support decisions made at the program level.

Another obvious, yet important benefit of the use of concept mapping with youth populations is that it is easily made into a developmentally appropriate activity for multiple age groups. However, the presence of trained researchers during the activities was important. 


\section{Future Considerations}

Future research should explore how concept mapping can be adapted for use with other youth populations. The youth involved in this study were from a normative sample. Populations of particular interest include youth living in residential facilities, incarcerated youth, disabled youth, and younger/pre-literate children.

\section{References}

Benson, P.L., Scales, P.C., Hamilton, S.F., \& Sesma, A., Jr. (2006). Positive youth development: Theory, research and applications. In W. Damon \& R.M. Lerner (Series Ed.) \& W. Damon (Vol. Ed.), Handbook of child psychology: Vol. 1. Theoretical models of human development ( $6^{\text {th }}$ ed.). New York: Wiley.

Brown, J.S. (2006, February 10). A collaborative approach to understanding the components of successful youth development programs. Retrieved May 28, 2006., from

http://www.actforyouth.net/documents/Dissemination\%20Report\%2081.2.2005.pdf

Brown, J.S. (2005). So many ideas, so little time: Statement synthesis in a youth development context. Paper presented at the annual meeting of the American Evaluation Association, Toronto, Canada.

Eisinger, A., \& Senturia, K. (2001). Doing community-driven research: A description of Seattle partners for healthy communities. Journal of Urban Health, 78(3), 519-534.

Green, L. W., \& Mercer, S. L. (2001). Can public health researchers and agencies reconcile the push from funding bodies and the pull from communities? American Journal of Public Health, 91(12), 1926-1929.

Higgins, D. L., \& Metzler, M. (2001). Implementing community-based participatory research centers in diverse urban settings. Journal of Urban Health, 78(3), 488-494.

Krieger, J., Allen, C., Cheadle, A., Ciske, S., Schier, J. K., Senturia, K., et al. (2002). Using community-based participatory research to address social determinants of health: Lessons learned from Seattle partners for healthy communities. Health Education \& Behavior, 29(3), 361-382.

Lantz, P. M., Viruell-Fuentes, E., Isreal, B. A., Softley, D., \& Guzman, R. (2001). Can communities and academia work together on public health research? Evaluation results from a community-based participatory research in Detroit. Journal of Urban Health-Bulletin of the New York Academy of Medicine, 78(3), 495-507.

Macaulay, A. C., Commanda, L. E., Freeman, W. L., Gibson, N., McCabe, M. L., Robbins, C. M., et al. (1999). Participatory research maximizes community and lay involvement. British Medical Journal, $319(7212)$, 774-778. 
National Research Council \& Institute of Medicine (Eds.). (2002). Community programs to promote youth development. Washington, DC: National Academy Press.

Trochim, W. M. K. (1989). An introduction to concept mapping for planning and evaluation. Evaluation and Program Planning, 12(1), 1-16.

Wallerstein, N. (1999). Power between evaluator and community: Research relationships within New Mexico's healthier communities. Social Science and Medicine, 49(1), 39-53.

(C) Copyright of Journal of Youth Development Bridging Research and Practice. Content may not be copied or emailed to multiple sites or posted to a listserv without copyright holder's express written permission. Contact Editor at: patricia.dawson@oregonstate.edu for details. However, users may print, download or email articles for individual use.

ISSN 2325-4009 (Print); ISSN 2325-4017 (Online) 